\title{
Trait Aggressiveness and Hockey Penalties: Predicting Hot Tempers on the Ice
}

\author{
Brad J. Bushman and Gary L. Wells \\ Iowa State University
}

\begin{abstract}
Previous studies examining the validity of measures of trait aggressiveness either have been retrospective studies or have used laboratory aggression as the criterion behavior. Can a measure of trait aggressiveness predict nonlaboratory physical aggression? The Physical Aggression subscale of the Aggression Questionnaire was completed by 91 high school hockey players prior to the start of the season. At the end of the season, these trait aggressiveness scores were regressed on minutes in the penalty box for aggressive penalties (e.g., fighting, slashing, tripping) and minutes in the penalty box for nonaggressive penalties (e.g., delay of game, illegal equipment, too many players). As expected, preseason trait aggressiveness scores predicted aggressive penalty minutes $(r=.33)$ but not nonaggressive penalty minutes $(r=.04)$.
\end{abstract}

Informal observation suggests that some people are especially likely to become involved in aggressive interactions. Individual differences are critical to understanding human aggression. The personality trait of aggression is referred to as trait aggressiveness. Trait aggressiveness can be measured using self-report personality scales, aggression nominations by others (e.g., peers, teachers, counselors), and violent histories. Longitudinal studies have shown that trait aggressiveness, regardless of how it is measured, is about as stable over time as intelligence (e.g., Olweus, 1979). In this article, we focus on selfreport personality scales because they are the most frequently used measure of trait aggressiveness and because they are easy and inexpensive to administer.

We sought evidence that a common pencil-and-paper measure of trait aggressiveness could predict aggressive behaviors outside of the laboratory. If a measure of trait aggressiveness can predict later aggressive behaviors, such a measure might prove useful for identifying, from a larger population, a subset of individuals who could

Brad J. Bushman and Gary L. Wells, Department of Psychology, Iowa State University.

We thank Greg Cigrand, League Commissioner of the Iowa High School Hockey League, for sending us the game sheets for the 1997 season. We thank the participating players, players' parents, and coaches of the Iowa High School Hockey League for their cooperation. We also thank Harnam Singh and Brad Wibicki for coding the data and Aaron Wells for his assistance in collecting the data.

Correspondence concerning this article should be addressed to Brad J. Bushman, Department of Psychology, Iowa State University, Ames, Iowa 50011-3180. Electronic mail may be sent to bushman@iastate.edu. most benefit from intervention or focused treatments (e.g., anger control workshops) prior to their being placed in certain settings. Alternatively, scores on such a measure might be useful for deciding which individuals might be best suited for particular jobs in which anger control needs to be especially high.

\section{Laboratory Studies Using Personality Scores to Predict Aggressive Behavior}

The most widely used self-report measure of trait aggressiveness is the Buss-Durkee Hostility Inventory (Buss \& Durkee, 1957), or its revision, the Aggression Questionnaire (Buss \& Perry, 1992). Numerous studies have used these inventories to predict how laboratory participants behave in delivering ostensible electric shock or white noise to a confederate (e.g., Bushman, 1995; Cleare \& Bond, 1995; Giancola \& Zeichner, 1995a, 1995b; Hammock \& Richardson, 1992; Knott, 1970; Larsen, Coleman, Forbes, \& Johnson, 1972; Leibowitz, 1968; Pihl, Lau, \& Assaad, 1997; Scheier, Buss, \& Buss, 1978; Shemberg, Leventhal, \& Allman, 1968). In these studies, those who scored higher on the hostility measure delivered greater levels or longer durations of the unpleasant stimulus to the confederate, particularly if the confederate had insulted or otherwise angered them. Such findings are used to argue that the inventories developed by Buss and his colleagues have predictive validity. Although the current authors accept these laboratory paradigms as valid measures of aggressive behaviors (Anderson \& Bushman, 1997; also see Berkowitz \& Donnerstein, 1982), others have been less convinced (e.g., Gottfredson \& Hirschi, 1993; Kane, Joseph, \& Tedeschi, 1976; Tedeschi \& Quigley, 1996). 
Laboratory studies in general are often criticized for their "artificiality.' For example, Babbie (1975) stated

The greatest weakness of laboratory experiments lies in their artificiality. Social processes observed to occur within a laboratory setting might not necessarily occur within more natural social settings. (p. 254)

Laboratory studies typically use a limited sample of participants (e.g., college students), placed in a sterile setting (e.g., a university laboratory), performing tasks that bear little resemblance to the tasks they perform in the real world.

Laboratory aggression studies in particular tend to be cited as examples of trivial studies that have no bearing on the real world. In the real world, people do not harm others by giving them electric shocks or noise blasts. Indeed, the threat of electric shock can hardly be representative of the dangers faced by anyone except electricians and introductory psychology students who participate in laboratory aggression studies.

To the extent that there is resistance to laboratory paradigms as valid measures of aggression, then using individual difference measures to predict laboratory aggression is not particularly strong evidence of predictive validity. In this study, we used personality measures to predict real world aggression.

\section{Studies Relating Personality Scores to Aggressive Behaviors Outside the Lab}

There are difficulties in using personality measures to predict aggression because aggressive behaviors are rare occurrences. If the behavior is rarely observed in the population from which the sample is taken, huge sample sizes are required to observe a sufficient number of cases of the aggressive behavior. Hence, studies relating personality measures to violent behavior outside of the lab have been retrospective studies (i.e., the behavior occurred before the measure was taken). In these retrospective studies, populations are identified who have engaged in the behavior, and then they are given the personality measure. Their postbehavioral personality score is then compared to some other group that has not engaged in the aggressive behavior. From this kind of work, we know that there are mean differences on the Buss-Durkee Hostility Inventory between violent and nonviolent criminals (Gunn \& Gristwood, 1975; Selby, 1984; Syverson \& Romney, $1985)$, between domestically violent and nonviolent men (Maiuro, Cahn, Vitaliano, Wagner, \& Zegree, 1988), between violent and nonviolent patients (Lange, Dehghani, \& De Beurs, 1995; Maiuro et al., 1988) between violent and nonviolent alcoholics (Renson, Adams, \& Tinklenberg, 1978), and between violent and nonviolent adolescent offenders (Boone \& Flint, 1988; Lothstein \&
Jones, 1978). Although these are important studies, the fact that they are retrospective means that they are not assessments of predictive validity of the Buss-Durkee Hostility Inventory. In retrospective studies, one does not know the Buss-Durkee Hostility Inventory scores of violent people prior to the occurrence of the aggressive behaviors. Perhaps their aggressive episodes caused changes in their self-perceptions, leading them later to report greater hostility on the inventory. Although we believe that these retrospective studies are reasonable evidence of the validity of the Buss-Durkee Hostility Inventory as a measure of aggressive personality, we accept the general argument regarding the limitations of retrospective studies.

We sought evidence that a personality measure of physical aggression at one time could be used to predict aggressive physical behaviors at later times outside of a laboratory setting. The primary reason that such studies have not been conducted, we believe, is that identifiable physical aggression (e.g., violent crime) outside of the devised lab paradigms is a relatively low base-rate behavior. The Federal Bureau of Investigation (FBI) classifies violent crime as offenses of murder, aggravated assault, forcible rape, and robbery. Based on the 1995 national statistics, for example, it would require 100,000 people in order to find 719 victims of violent crime (U.S. FBI, 1996). Many of these offenders cannot be identified. Even if they could be identified and located, the number of perpetrators would be less than the 719 per 100,000 owing to the fact that many of the victims were assaulted by the same perpetrator.

One setting in which there is a relatively high base rate of physical aggression by identifiable individuals is in the game of ice hockey. Ice hockey is a highly skilled, mostly male populated sport that requires considerable coordination, aerobic conditioning, and body contact. Fighting is not an official part of hockey. However, fighting is a part of the culture of hockey. In both North America and Europe, fighting in a hockey game is common enough in some adult leagues that one can often observe two or three fights in a single game. There are popularly marketed videos in National Hockey League cities of NHL hockey fights, showing hours of players' on-ice fights from the previous season. The old joke "I went to a fight and a hockey game broke out" is well understood by hockey enthusiasts. This is not to say that fighting is accepted in hockey. Fighting results in a penalty in all leagues of hockey.

In hockey, fighting is a specific penalty that is given to a player who strikes another player, usually with his or her fists. Slashing, on the other hand, involves using a hockey stick to strike another player; roughing involves shoving (e.g., against the boards or rink wall); tripping involves using the hockey stick to pull the skates from 
under an opposing player, and so on. We consider all of these penalties to be aggressive behaviors. On the other hand, there are penalties that we do not consider aggressive, such as illegal equipment or too many players on the ice. Hence, we do not equate a hockey penalty per se with aggressive behavior, but the vast majority of hockey penalties are aggressive behaviors involving striking with fists, striking with sticks, tripping, shoving, ramming a player into the rink walls, and so on.

We chose to use high school hockey players as our sample for several reasons. First, high school hockey likely includes a more diverse population base than does college or semiprofessional hockey. Few high school players go on to play college or semiprofessional hockey, and at some point in the weeding process the players are likely to represent a rather peculiar sample in unknown ways. Pre-high-school hockey players were considered for possible inclusion in our sample, but the behavior of interest (aggression on the ice) is much less frequent in such leagues. Another reason why pre-high-school leagues can be problematic is that the quality of referees is highly variable, and games often are held with only one referee. In single-referee games, the referee must watch for offside calls and other details of play rather than penalties per se. In high school hockey there are at least two and usually three referees, one of whom is designated specifically to watch for penalties. Our data depend greatly on the validity of the referees' calls. Behaviors such as slashing, boarding, and tripping often are missed by referees in prehigh-school leagues, owing to the referees' inexperience and the use of only one referee to catch the behaviors. There were also practical reasons to use high school players as our sample, such as the cooperation of the Iowa High School Hockey League.

We predicted that scores on the Aggression Questionnaire (Buss \& Perry, 1992) would be positively correlated with the number of minutes penalized for aggressive infractions (e.g., slashing, boarding, tripping) but would be uncorrelated with the number of minutes penalized for nonaggressive infractions (e.g., delay of game, illegal equipment, too many players).

\section{Method}

\section{Participants}

Participants were hockey players recruited from the Iowa High School Hockey League, which consists of 10 teams from Iowa, Missouri, and Nebraska. All hockey players in the league were boys. After practice sessions began, but before any games were played, coaches gave all players a questionnaire and a consent form. The consent form required the signature of the boy and his parent or guardian. Of the 200 boys who received questionnaires and consent forms, 91 returned them before the 1997 season began, for a return rate of about $46 \%$. In exchange for their voluntary participation, participants received two packets of hockey cards (valued at about \$2).

Although we had Aggression Questionnaire scores only for the $46 \%$ who responded, at the end of the season we had penalty scores for the entire population. Hence, for comparison purposes, we tabulated season aggressive and nonaggressive penalty minutes for a sample of 91 nonrespondent hockey players to compare to the 91 respondents. Respondents and nonrespondents didn't differ in aggressive penalty minutes, $M=18.5, S D$ $=19.1$ and $M=23.9, S D=24.2$, respectively, $t(180)=1.70$, $p>.05$. Likewise, respondents and nonrespondents didn't differ in nonaggressive penalty minutes, $M=0.4, S D=1.0$ and $M$ $=0.3, S D=0.7$, respectively, $t(180)=0.70, p>05$. Thus, the respondents and nonrespondents appear to be comparable.

\section{Measure of Trait Aggressiveness}

We used the Physical Aggression subscale of the Aggression Questionnaire (Buss \& Perry, 1992) to measure trait aggressiveness. The Aggression Questionnaire, a revised version of the Buss-Durkee Hostility Inventory (Buss \& Durkee, 1957), has four subscales measuring, respectively, physical aggression, verbal aggression, anger, and hostility. Although some studies have shown that the entire scale is related to aggression, more common are studies in which aggression is predicted from scores on various subscales. We used the Physical Aggression subscale because nearly all hockey penalties are physical in nature.

The Physical Aggression subscale of the Aggression Questionnaire contains nine items along with a Likert-type scale for each item ranging from 1 (extremely uncharacteristic of me) to 5 (extremely characteristic of me). Sample items from the subscale include, "Once in a while I cannot control my urge to strike another person," "If somebody hits me, I hit back," and "I get into fights a little more than the average person."

The coefficient alpha for the Physical Aggression subscale is .85 , and the test-retest correlation is .80 (Buss \& Perry, 1992). In the present sample, the coefficient alpha for the subscale was .77. For a sample of 612 male college students, Buss and Perry reported a mean Physical Aggression score of 24.3 with a standard deviation of 7.7. In the present sample, the mean Physical Aggression score was 24.3 with a standard deviation of 6.2. The mean level of physical aggressiveness in the present sample was the same as the level of physical aggressiveness observed in Buss and Perry's normative sample of college students, but the range of scores was somewhat more restricted. Hartley's (1950) test showed that the variances did differ, $F_{\max }(611,90)$ $=1.54, p<.05$.

The questionnaire also included a number of demographic variables such as the player's sex, age, height, weight, level of play (i.e., varsity or junior varsity), and position (i.e., center, left/right wing, left/right defense, goal). These variables were coded as possible covariates for the regression analysis.

\section{Procedure}

Participants completed the Physical Aggression subscale of the Aggression Questionnaire, the demographic characteristics, and the consent form prior to beginning the 1997 hockey season. From the original game sheets, we tabulated the number of 
minutes each player was penalized for each infraction. Most penalties are $2 \mathrm{~min}$, but penalties with injury potential (e.g., butt-ending, spearing, head butting, kicking, fighting, and grabbing another player's face mask) are $5 \mathrm{~min}$. In the rare case of attempt to injure, a 10-min game misconduct penalty is given. In extreme cases, a player is expelled for the rest of the game as well as for the next game. To be conservative, we coded the last penalty as $15 \mathrm{~min}$.

We divided hockey penalties into nonaggressive and aggressive categories. The nonaggressive penalties included no mouth guard, illegal equipment, too many players on the ice, delay of game, and bench minor. All of the nonaggressive penalties were 2 -min infractions. To be conservative, we classified the remaining penalties as aggressive. We summed the total number of minutes penalized for each type of penalty.

From the game sheets we also tabulated the number of games played, the number of assists, and the number of goals. These variables were coded as possible covariates for the regression analysis.

\section{Results}

The average number of infractions for each type of penalty is given in Table 1. As can be seen in Table 1, the base rates for the individual penalties were low. Thus, we could not regress the trait aggressiveness scores on individual penalties; instead, we collapsed across the aggressive penalties to create an aggressive penalty category,

Table 1

Mean Number of Minutes Penalized per Player for Each Type of Aggressive and Nonaggressive Hockey Penalty

\begin{tabular}{lcr}
\hline \multicolumn{1}{c}{ Infraction } & $M$ & $S D$ \\
\hline Aggressive penalities & 18.49 & 19.10 \\
Roughing & 4.64 & 5.83 \\
Misconduct & 3.63 & 6.59 \\
Tripping & 1.82 & 2.76 \\
Interference & 1.54 & 2.68 \\
Holding & 1.10 & 2.39 \\
Hooking & 0.92 & 1.56 \\
Slashing & 0.90 & 1.84 \\
Cross-checking & 0.88 & 1.91 \\
High-sticking & 0.81 & 1.46 \\
Unsportsmanlike conduct & 0.64 & 1.33 \\
Elbowing & 0.55 & 1.58 \\
Fighting & 0.55 & 1.74 \\
Boarding & 0.13 & 0.50 \\
Charging & 0.13 & 0.50 \\
Butt-ending & 0.11 & 0.74 \\
Kneeing & 0.07 & 0.36 \\
Face mask & 0.05 & 0.52 \\
Late hit & 0.02 & 0.21 \\
Nonaggressive penalties & 0.40 & 1.00 \\
Bench minor & 0.18 & 0.71 \\
Delay of game & 0.13 & 0.58 \\
Too many men & 0.04 & 0.29 \\
Illegal equipment & 0.02 & 0.21 \\
No mouth guard & 0.02 & 0.21 \\
\hline No & &
\end{tabular}

Note. $\quad N=91$. and we collapsed across the nonaggressive penalties to create a nonaggressive penalty category.

The data were analyzed using a repeated measures regression analysis, with type of penalty (i.e., nonaggressive, aggressive) as the repeated measures variable. Trait aggressiveness, as measured by the Physical Aggression subscale of the Aggression Questionnaire (Buss \& Perry, 1992), was treated as a continuous variable in the model. Of all the potential covariates measured, only the number of games played and the number of assists were related to hockey penalties. The latter two variables were both positively related to the total number of minutes penalized ( $r \mathrm{~s}=.38$ and .41 , respectively, $p<.05$ for both).

The analysis revealed that aggressive penalties were more common than nonaggressive penalties and that trait aggressiveness was positively correlated with minutes penalized, $F(1,87)=15.00$ and 6.66 , respectively, $p<.05$ for both. These main effects, however, were qualified by the expected Trait Aggressiveness $\times$ Type of Penalty interaction, $F(1,87)=5.76, p<.05$. Trait aggressiveness was positively related to aggressive hockey penalties and was unrelated to nonaggressive hockey penalties, $F(1$, $87)=10.99, p<.05, r=.33$, and $F(1,87)=0.11, p$ $>.05, r=.04$, respectively. This interaction is depicted in Figure 1 using different regression lines for aggressive and nonaggressive hockey penalties for the range of trait aggression scores obtained in the study (see Aiken \& West, 1991). To make the figure easier to interpret, both types of penalties are given in standard deviation units. In addition, both the number of games played and the number of assists made were positively correlated with total minutes penalized, $F(1,87)=4.42$ and 11.14 , respectively, $p<.05$ for both. The model $R^{2}$ was .27 for aggressive penalties and .03 for nonaggressive penalties.

\section{Discussion}

We conducted this study to see if the Aggression Questionnaire (Buss \& Perry, 1992) measured at one time could predict aggressive behavior in a nonlaboratory setting at a later time. The obtained correlation of .33 between preseason measures on the Aggression Questionnaire and aggressive hockey penalties over the course of the season is evidence for predictive validity of the inventory. The low and nonsignificant correlation between Aggression Questionnaire scores and nonaggressive penalties indicates that the inventory is not just predicting penalties, such as delay of game, but rather is predicting behaviors that are physically aggressive, such as punching other players or hitting them with a stick.

Although some might not be highly impressed with a .33 correlation, the predictive value of the correlation is not trivial. Suppose, for instance, the base rate for the to-be-predicted behavior is $50 \%$. Using Rosenthal and 


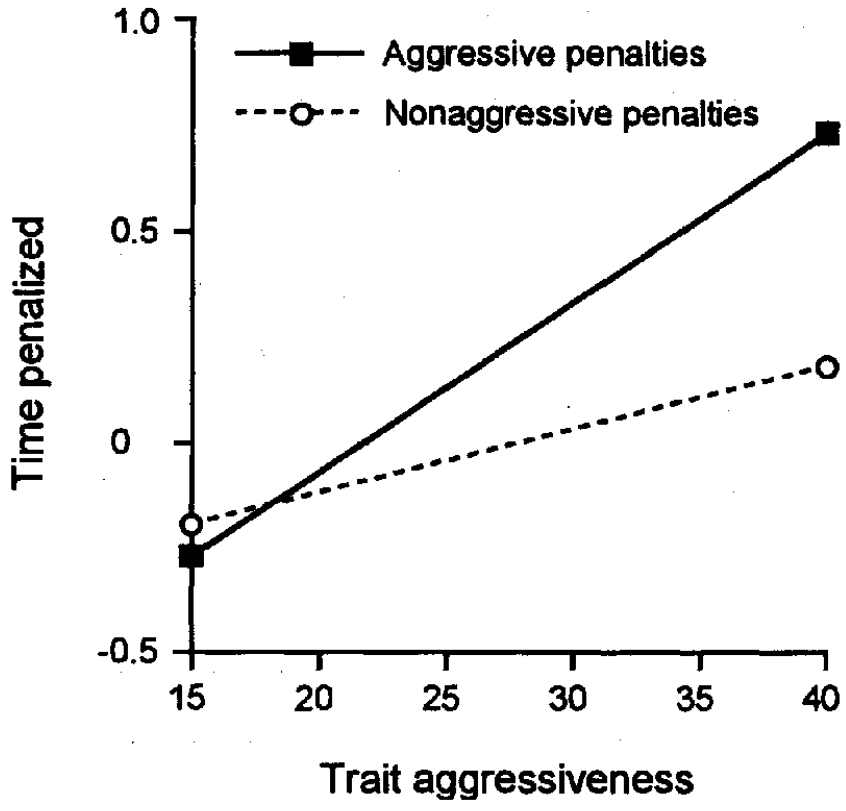

Figure 1. Relations between trait aggressiveness and aggressive and nonaggressive hockey penalties.

Rubin's (1982) Binomial Effect Size Display, we note that the .33 correlation is equivalent to the behavior being exhibited for $66.5 \%$ of those above the median on the predictor but only $33.5 \%$ of those below the median on the predictor. Moreover, the correlation obtained in this study is similar in magnitude to effects observed for other individual difference and situational variables in aggression research (Anderson \& Bushman, 1997). This correlation is particularly impressive when one considers that there is error in the measure of aggression (e.g., some penalties are missed by the referees), the Aggression Questionnaire is a general measure that was not designed with ice hockey in mind, and the self-selection nature of high school hockey is likely to have restricted the range of scores (compared to all high school students) to some extent.

Unlike studies using this inventory to predict levels of electric shock or white noise delivered to a confederate in an experiment (e.g., Bushman, 1995; Cleare \& Bond, 1995; Giancola \& Zeichner, 1995a; Giancola \& Zeichner, 1995b; Hammock \& Richardson, 1992; Knott, 1970; Larsen et al., 1972; Leibowitz, 1968; Pihl et al., 1997; Scheier et al., 1978; Shemberg et al., 1968), these data show that the inventory can predict aggressive behaviors outside of the laboratory. Unlike retrospective studies showing mean differences between known violent and nonviolent persons (e.g., Boone \& Flint, 1988; Gunn \& Gristwood, 1975; Maiuro et al., 1988; Lange et al., 1995; Lothstein \& Jones, 1978; Renson et al., 1978; Selby, 1984; Syverson \& Romney, 1985), these data show that there were differences in scores on the Aggression Questionnaire prior to the aggressive behavior. Hence, we believe that the current data represent a "third leg" on which an argument can be made for the validity of the Aggression Questionnaire as a measure of individual differences in aggressive propensities.

This is the first study to show predictive validity for the Aggression Questionnaire on nonlaboratory aggression. These results suggest that there might be some merit in using the Aggression Questionnaire to screen applicants for positions in which aggression is a particularly problematic behavior. Similarly, there might be merit in the idea of using the Aggression Questionnaire in school systems to identify students at high risk of violence. We are not, however, advocating the use of the Aggression Questionnaire for employment screening or for predicting violence in schools at this point in time. Although we believe that hockey penalties, such as slashing, boarding, fighting, and so on, are aggressive behaviors, we are reluctant to equate these behaviors with other kinds of violence. We recommend that any use of the Aggression Questionnaire as a predictive device first be validated in the relevant applied setting using measures of the specific aggressive or violent behaviors of concern.

\section{References}

Aiken, L. S., \& West, S. G. (1991). Multiple regression: Testing and interpreting interactions. Newbury Park, CA: Sage.

Anderson, C. A., \& Bushman, B. J. (1997). External validity of "trivial" experiments: The case of laboratory aggression. Review of General Psychology, 1, 19-41.

Babbie, E. R. (1975). The practice of social research. Belmont, CA: Wadsworth.

Berkowitz, L., \& Donnerstein, E. (1982). External validity is more than skin deep: Some answers to criticism of laboratory experiments. American Psychologist, 37, 245-257.

Boone, S. L., \& Flint, C. (1988). A psychometric analysis of aggression and conflict-resolution behavior in Black adolescent males. Social Behavior and Personality, 16, 215-226.

Bushman, B. J. (1995). Moderating role of trait aggressiveness in the effects of violent media on aggression. Journal of Personality and Social Psychology, 69, 950-960.

Buss, A. H., \& Durkee, A. (1957). An inventory for assessing different kinds of hostility. Journal of Consulting Psychology, $21,343-349$.

Buss, A. H., \& Perry, M. (1992). The Aggression Questionnaire. Journal of Personality and Social Psychology, 63, 452-459.

Cleare, A. J., \& Bond, A. J. (1995). The effect of tryptophan depletion and enhancement of subjective behavioural aggression in normal male subjects. Psychopharmacology, 118, 7281.

Giancola, P. R., \& Zeichner, A. (1995a). Alcohol related aggression in males and females: Effects of blood alcohol concentration, subjective intoxication, personality, and provocation. $A l$ coholism: Clinical and Experimental Research, 19, 130-134. 
Giancola, P. R., \& Zeichner, A. (1995b). Construct validity of a competitive reaction-time aggression paradigm. Aggressive Behavior, 21, 199-204.

Gottfredson, M. R., \& Hirschi, T. (1993). A control theory interpretation of psychological research on aggression. In R. B. Felson \& J. T. Tedeschi (Eds.), Aggression and violence: Social interactionist perspectives (pp. 47-68). Washington, DC: American Psychological Association.

Gunn, J., \& Gristwood, J. (1975). Use of the Buss-Durkee Hostility Inventory among British prisoners. Joumal of Consulting and Clinical Psychology, 43, 590.

Hammock, G. S., \& Richardson, D. R. (1992). Predictors of aggressive behavior. Aggressive Behavior, 18, 219-229.

Hartley, H. D. (1950). The maximum $F$-ratio as a short-cut test for heterogeneity of variance. Biometrika, 37, 308-312.

Kane, T. R., Joseph, J. M., \& Tedeschi, J. T. (1976). Person perception and the Berkowitz paradigm for the study of aggression. Journal of Personality and Social Psychology, 33, 663-673.

Knott, P. (1970). A further methodological study of the measurement of interpersonal aggression. Psychological Reports, $26,807-809$.

Lange, A., Dehghani, B., \& De Beurs, E. (1995). Validation of the Dutch adaptation of the Buss-Durkee Hostility Inventory. Behavioral Research Therapy, 33, 229-233.

Larsen, K. S., Coleman, D., Forbes, J., \& Johnson, R. (1972). Is the subject's personality or the experimental situation a better predictor of a subject's willingness to administer shock to a victim? Journal of Personality and Social Psychology, 22, 287-295.

Leibowitz, G. (1968) . Comparison of self-report and behavioral techniques of assessing aggression. Journal of Consulting and Clinical Psychology, 32, 21-25.

Lothstein, L. M., \& Jones, P. (1978). Discriminating violent individuals by means of various psychological tests. Journal of Personality Assessment, 42, 237-243.

Maiuro, R. D., Cahn, T. S., Vitaliano, P. P., Wagner, B. C., \&
Zegree, J. B. (1988). Anger, hostility, and depression in domestically violent versus generally assaultive men and nonviolent control subjects. Journal of Consulting and Clinical Psychology, 56, 17-23.

Olweus, D. (1979). Stability of aggressive reaction patterns in males: A review. Psychological Bulletin, 86, 852-875.

Pihl, R. O., Lau, M. L., \& Assaad, J. M. (1997). Aggressive disposition, alcohol, and aggression. Aggressive Behavior, 23, 11-18.

Renson, G. J., Adams, J. E., \& Tinklenberg, J. R. ( 1978). BussDurkee assessment and validation with violent versus nonviolent chronic alcohol abusers. Journal of Consulting and Clinical Psychology, 46, 360-361.

Rosenthal, R., \& Rubin, D. B. (1982). A simple, general purpose display of magnitude of experimental effect. Journal of Educational Psychology, 74, 166-169.

Scheier, M. F., Buss, A. H., \& Buss, D. M. (1978). Self-consciousness, self-report of aggressiveness, and aggression. Journal of Research in Personality, 12, 133-140.

Selby, M. J. (1984). Assessment of violence potential using measures of anger, hostility, and social desirability. Journal of Personality Assessment, 48, 531-544.

Shemberg, K. M., Leventhal, D. B., \& Allman, L. (1968). Aggression machine performance and rated aggression. Journal of Experimental Research in Personality, 3, 117-119.

Syverson, K. L., \& Romney, D. M. (1985). A further attempt to differentiate violent from nonviolent offenders by means of a battery of psychological tests. Canadian Journal of Behavioural Science, 17, 87-92.

Tedeschi, J. T., \& Quigley, B. M. (1996). Limitations of laboratory paradigms for studying aggression. Aggression and Violent Behavior, 1, 163-177.

U.S. Federal Bureau of Investigation. (1996). Uniform crime reports. Washington, DC: U.S. Government Printing Office.

Received January 29, 1998 Revision received May 6, 1998 Accepted May 7, 1998 